\title{
A STRUCTURED 8 Disciplines METHOdOLOGY TO DEVELOP PROBLEM SOLVING SKILLS AMONG ENGINEERING STUDENTS DURING INTERNSHIP:A SYSTEMATIC LITERATURE REVIEW
}

\begin{abstract}
Murugan Subramaniam*
Doctoral Candidate in Social Science and Humanities, Faculty of Education Universiti Teknologi Malaysia, 81310 UTM, Skudai, Johor Darul Takzim Malaysia

\section{Muhammad Khair Noordin}

Senior Lecturer in Social Science and Humanities, Faculty of Education, Universiti Teknologi Malaysia, 81310 UTM, Skudai, Johor Darul Takzim Malaysia
\end{abstract}

*Corrosponding author's Email: murugan2@graduate.utm.my

Peer-review under responsibility of $3^{\text {rd }}$ Asia International Multidisciplanry Conference 2019 editorial board (http://www.utm.my/asia/our-team/) (C) 2019 Published by Readers Insight Publisher, lat 306 Savoy Residencia, Block 3 F11/1,44000 Islamabad. Pakistan, info@readersinsight.net This is an open access article under the CC BY-NC-ND license (http://creativecommons.org/licenses/by-nc-nd/4.0/). 


\section{$R_{i}$}

\section{Science Proceedings Series (SPS) \\ www.readersinsight.net/SPS}

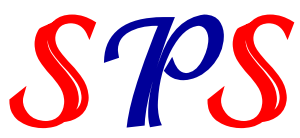

\section{R E S E A R C H H I G H L I G H T S}

Current survey shows there are 1 out of 5 graduates are unemployed (1). Lack of non technical skills among graduates be one of the main reason for unemployment.Data shows Problem Solving Skills is the second most important non technical skill sought by employers (2); The studies show that the problems cannot be solved by using the same kind of thinking approach applied at the moment it was created. Therefore, a systematic analytical skill is required to handle the engineering related problems happening at manufacturing environment or engineering workplace. The purpose of this paper is to analyze the existing literature about Problem Solving skills for graduate engineers through a systematic literature review. This paper analyses literature through electronic databases mainly from Scopus and Web of Science. This paper summarizes types of problem solving skills applied in the engineering field as of now. Based on that, engineers can differentiate and understand the approach of the problem solving skills in the industrial environment to improve the failures and increase productivity.

Keywords:- Problem Solving, Graduate, Engineer, 8D, Methodology, Internship

\section{GRAPHICAL ABSTRACT}

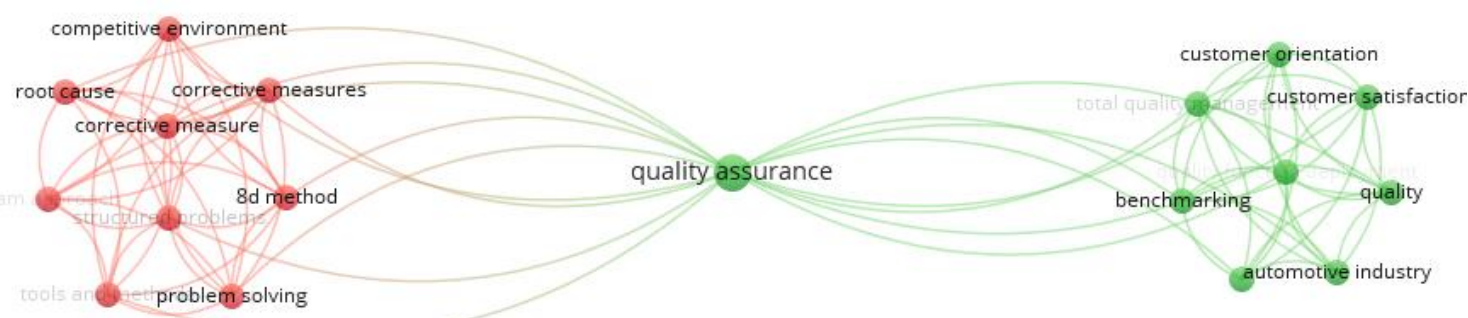

Fig. 1a) The analysis of abstract and title for 8D Problem Solving Methodology

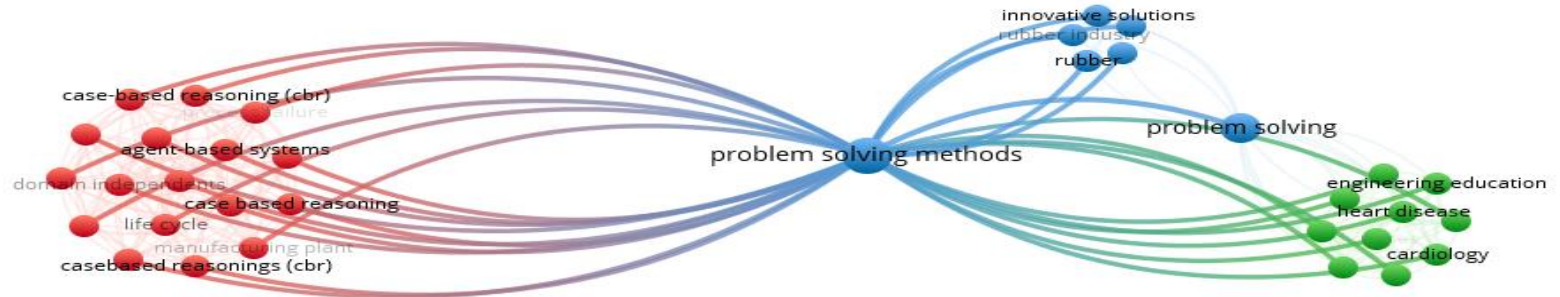

Fig. 1b) The Analysis of Abstract and Title for 8D Problem Solving Methodology and Engineering Education

According to Fig. 1(a) 8D Methodology is one of the important approach to develop systematic problem solving skills in work place. The link shows very strong relationship between problem solving and product quality in working environment. But we can't see any clear connection between engineering students and 8D Methodology

Base on Fig. 1(b) once we add keyword "Engineer" the network shows the 8D Methodology disappeared and replaced with problem solving methods (majority are mathematical problem solving \& minority work place engineering problem). High occurrences of "problem solving methods" connect perfectly with engineering education. But still the studies shows graduate engineers do not have sufficient problem solving skills. This shows there are some differences in developing problem solving skills among engineering students (universities) and graduate engineers(employers). 


\section{$R_{i}$}

\section{Science Proceedings Series \\ (SPS) \\ www.readersinsight.net/SPS}

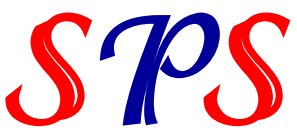

\section{RESEARCH OBJECTIVES}

The aims of this paper is to give an overview about the important of problem solving skills at industrial environment and develop the industrial base problem solving skills among engineering students during internship through structured 8D Methodology. This will carry some weightage in their resume during interview and help for fast job placement.

Research on student-learning outcomes showed that university graduates were not necessarily developing the skills required by the industry. The research suggested that there is a shortfall in important skills being developed among university students such as communication, decision- making, problem-solving, leadership, emotional intelligence and social ethics. Research pointed to a mismatch between graduate skills developed during university studies and the skills needed in the workplace (3). Research further highlighted that in a globalized work environment, university graduates tend to be ill-prepared in their ability to work with people of different cultural backgrounds(3). Although, there are many types of non-technical skills required in many engineering working environments; the problem solving skills still remain as the most needed skill by the employers (NACE Job Outlook, 2019). Practicing engineers are hired, retained and rewarded for solving problems, so engineering students should learn how to solve workplace problems. Workplace engineering problems are substantively different from the kinds of problems that engineering students solve most often in a classroom; therefore, learning to solve classroom problems does not necessarily prepare engineering students to solve workplace problems(4).

\section{MATERIALS AND METHODS}

A systematic literature review begins with the aid of VOSviewer software version 1.6.11. The software supports to simulate ris, csv and txt format from WoS and Scopus and to convert into desired form named bibliometric maps, network visualization, overlay visualization and density visualization(5). Initial data collection were extracted from (WoS) Web-of-Science and Scopus with keywords; Problem Solving Skill Among Graduate Engineer. The data was compiled as of March 31, 2019 and narrowed down to engineering field alone. Altogether, 1041 Scopus documents and $246 \mathrm{WoS}$ documents were shortlisted for the systematic literature review. Data shows that 30\% of the WoS documents and 59\% of the Scopus documents were selected for citation. The balance remains as zero citation and co citation.

The purpose for selecting Scopus and Web-of-Science for the literature review is because both websites have huge number of data collection and those data is sufficient to perform the systematic literature review. Table 1, shows the systematic literature review protocol.

Table 1. Systematic Literature Review Protocol

\begin{tabular}{|c|c|}
\hline Description & Conditions / Results \\
\hline & $\begin{array}{l}\text { To conduct a systematic literature review Problem Solving Skills Among } \\
\text { Graduate Engineers at Manufacturing environment }\end{array}$ \\
\hline \multirow[t]{2}{*}{ Objective } & $\begin{array}{l}\text { To analyze the existing research on problem solving skills among graduate } \\
\text { Engineers }\end{array}$ \\
\hline & To determine the gap and future research direction \\
\hline Source of Data & Scopus and Web-Of-Science \\
\hline Area of Interest & $\begin{array}{l}\text { Problem solving Skills Among Graduate Engineers at workplace / } \\
\text { Manufacturing environment }\end{array}$ \\
\hline Search Field & $\begin{array}{l}\text { Workplace competence; Problem Solving Skills; Manufacturing; Engineering; } \\
\text { 8D; }\end{array}$ \\
\hline Publication Years & 1968-2019 Scopus \& 1996-2019 Web Of Science \\
\hline Covered Period & 31/Mac/2019 \\
\hline
\end{tabular}




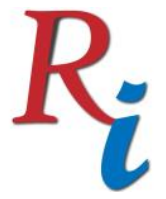

\title{
Science Proceedings Series (SPS) \\ www.readersinsight.net/SPS
} STS

Preliminary

Document Selected

Engineering Related

Papers Screened

Documents Analysis Information based on content analyzed with the aid of VOSviewer

\author{
1148-Scopus \& 2048-WoS \\ 1041 - Scopus \& $246-$ WoS
}

\section{RESULTS}

The systematic literature review gave an overview that the universities mainly focus in engineering education and closely tie it with design problems; classroom problems; mathematical problems and the analysis shows that "real problem" and "non-technical problems" are paid less attention especially in engineering related problem solving skills. The bibliometric network shows that Industries actively applying 8D methodology to solve industrial problem but engineering students are don't have sufficient exposure toward 8D Methodology. Therefore, employers and universities must give more attention to the engineering students toward 8D problem solving methodology during their stay in industries during internship to develop the problem solving skills.

\section{FINDINGS}

A structured 8D methodology and systematic assessment has to be carried out by employers and universities to assess the student's activities and the number of real engineering problems that have been handled by them during their Industrial training period. Such a assessment will produce "work ready" engineers and will increase the employability rate among graduate engineers.

\section{ACKNOWLEDGEMENT}

State any acknowledgement if it is required.

\section{REFERENCES}

1. Site J. 2018 salary report of $K$ city. 2018;(1).

2. $\quad$ To F, Members N, Price N. Job Outlook 2019. 2019;(November 2018).

3. Chenicheri sid naira arun patib dan patricia mertovaa. European Journal of Engineering Training effectiveness of engineering students : A case study. Taylor Fr. (March 2015):37-41.

4. Jonassen D, Strobel J, Lee C, Technologies L, Programme ET, Sciences L, et al. Everyday Problem Solving in Engineering: J Eng Educ. 2006;9(2):139-51.

5. $\quad$ Eck NJ Van, Waltman L. VOSviewer Manual. Manual. 2016;(version 1.6.4):1-28. 